\title{
Analisis Pengendalian Kualitas Produk Teh Hitam Di PT. Perkebunan Tambi Unit Perkebunan Bedakah Kabupaten Wonosobo Jawa Tengah
}

\section{The Analysis of Product Quality Control of Black Tea in PT. Perkebunan Tambi Bedakah Unit Wonosobo Regency Central Java}

\author{
Gresia Batubara*, Ni Made Suyastiri Yani Permai, Indah Widowati \\ Program Studi Agribisnis Jurusan Agribisnis, Fakultas Pertanian, Universitas \\ Pembangunan Nasional "Veteran" Yogyakarta \\ Jl. SWK 104 (Lingkar Utara) Condong Catur Yogyakarta Indonesia \\ *Email korespondensi : gresia.batubara29@gmail.com
}

Diterima tanggal : 3 Desember 2020 ; Disetujui tanggal : 4 Januari 2021

\begin{abstract}
This research was conducted in PT. Perkebunan Tambi Bedakah Unit Wonosobo regency, Central Java. The purpose of this research are (1) analyze the product quality control implementation on drying process of black tea in PT. Perkebunan Tambi Bedakah Unit; (2) know factors that cause the less optimal on drying process of black tea in PT. Perkebunan Tambi Bedakah Unit. The basic method used is descriptive with the implementation method is the case study. Method of determining respondents using the purposive method. Data types and sources are primary data and secondary data with data collection tehniques using observations, interviews, and documentations. This research uses four quality control tools are (1) check sheet; (2) X bar-Chart and R-Chart; (3) process capability; (4) fishbone diagram. The results showed that (1) the product quality control implementation on drying process of black tea in PT. Perkebunan Tambi Bedakah Unit is still in the spesification limit; (2) Factors that cause the less optimal on drying process of black tea in PT. Perkebunan Tambi Bedakah Unit are factors of raw materials, machinery, manpower, and environment.
\end{abstract}

Keywords : process capability, product quality, product quality control

\begin{abstract}
ABSTRAK
Penelitian ini dilakukan di PT. Perkebunan Tambi Unit Perkebunan Bedakah Kabupaten Wonosobo Jawa Tengah. Tujuan penelitian ini adalah (1) menganalisis pelaksanaan pengendalian kualitas pada proses pengeringan teh hitam di PT. Perkebunan Tambi Unit Perkebunan Bedakah; (2) mengetahui faktor-faktor yang menyebabkan kurang maksimalnya proses pengeringan teh hitam di PT. Perkebunan Tambi Unit Perkebunan Bedakah. Metode dasar yang digunakan adalah deskriptif dengan metode pelaksanaan adalah studi kasus. Metode penentuan responden menggunakan metode purposive. Macam dan sumber data ialah data primer dan data sekunder dengan teknik pengumpulan data menggunakan observasi, wawancara dan dokumentasi. Penelitian ini menggunakan empat alat pengendalian kualitas yaitu (1) lembar pemeriksaan; (2) $\mathrm{X}$ bar-Chart dan R-Chart; (3) kapabilitas proses; (4) diagram sebab akibat. Hasil
\end{abstract}


penelitian menunjukkan bahwa (1) Pelaksanaan pengendalian kualitas produk pada proses pengeringan teh hitam di PT. Perkebunan Tambi Unit Perkebunan Bedakah masih berada dalam batas spesifikasi (2) Faktor-faktor yang menyebabkan kurang maksimalnya proses pengeringan teh hitam di PT. Perkebunan Tambi Unit Perkebunan Bedakah adalah faktor bahan baku, mesin, tenaga keja, metode kerja dan lingkungan.

Kata Kunci : kapabilitas proses, kualitas produk, pengendalian kualitas produk

\section{PENDAHULUAN}

PT. Perkebunan Tambi merupakan Perkebunan Besar Swasta Nasional (PBSN) yang bergerak dalam bidang agroindustri dengan produk akhir teh hitam, teh hijau dan teh putih yang sebagian besar hasil produksinya untuk memenuhi permintaan pasar luar negeri. Seiring dengan semakin tingginya tingkat persaingan pasar terkhususnya pasar internasonal, PT. Perkebunan Tambi yang sudah bergerak di pasar ekspor dituntut untuk meningkatkan kualitas dan kinerja perusahaan dalam memproduksi produk karena konsumen semakin selektif dalam memilih dan menggunakan produk yang akan mereka konsumsi.

Salah satu strategi perusahaan untuk mendapatkan keunggulan bersaing adalah dengan terus-menerus meningkatkan kualitas produknya (Sidartawan, 2014). Inilah yang mendorong PT. Perkebunan Tambi untuk menerapkan konsep Total Quality Management terutama pada pengendalian kualitas. Menurut Gaspersz (2001), Manajemen Kualitas Terpadu atau Total Quality Management (TQM) didefinisikan sebagai suatu cara meningkatkan performansi secara terus menerus pada setiap level operasi atau proses, dalam setiap area fungsional dari suatu organisasi dengan menggunakan semua sumber daya manusia dan modal yang tersedia. Pengendalian kualitas menjadi salah satu fungsi yang penting dari suatu perusahaan, untuk itu kualitas produk harus ditangani oleh bagian pengendalian kualitas dalam perusahaan mulai dari pengendalian bahan baku, pengendalian kualitas proses produksi sampai produk siap untuk dipasarkan (Assauri, 2004).

Proses pengeringan di PT. Perkebunan Tambi Unit Perkebunan Bedakah dilakukan dengan menggunakan mesin dryer, dengan tujuan menghentikan aktivitas senyawa polifenol dalam teh dan menurunkan kadar air hingga 3-4\% 
Batubara, et.al., Analisis Pengendalian Kualitas Produk Teh Hitam Di PT ...

sehingga teh dapat dikatakan berkualitas baik. Kapasitas muatan dari mesin dryer I adalah 180 - $200 \mathrm{~kg}$ per jam dan kapasitas mesin dryer II adalah 100 - $120 \mathrm{~kg}$ per jam dengan suhu yang masuk pada mesin pengering $95-110^{\circ} \mathrm{C}$ dan suhu yang keluar $50-55^{\circ} \mathrm{C}$. Waktu yang digunakan dalam proses pengeringan teh hitam dari bubuk masuk hingga keluar dari mesin dryer adalah 20 - 25 menit dengan standar kadar air adalah 3-4\%.

Permasalahan yang sering timbul pada proses produksi dan dapat memengaruhi kualitas adalah adanya produk rusak, sehingga memerlukan langkah atau usaha untuk memecahkan masalah tersebut agar kualitas produk dapat terjaga dengan baik (Hariyanto, 2017). Pada proses pengeringan mesin dryer sering mengalami kendala seperti terjadinya fall trough yaitu banyaknya partikel teh yang jatuh ke bawah di dalam mesin dryer, hal ini disebabkan karena lubang trays yang terlalu besar. Kendala lain yang terjadi pada mesin adalah terjadinya blow out yaitu banyaknya partikel teh yang jatuh diluar mesin dryer, hal ini disebabkan oleh terlalu besarnya volume udara atau dikarenakan bahan baku yang berasal dari petikan kasar. Selain itu, kendala lain yang sering terjadi adalah pemberian suhu masuk dan suhu keluar pada mesin dryer yang terlalu tinggi akan mengakibatkan terjadinya produk teh hitam dengan kualitas rendah seperti case hardening, bakey, burn dan over fired. Case hardening adalah bagian luar partikel teh sudah kering tetapi bagian dalamnya masih basah yang mengakibatkan teh cepat berjamur dan kadar air lebih dari 4\%, hal ini dikarenakan pemberian suhu luar yang terlalu tinggi. Bakey, burn dan over fired adalah partikel teh yang terbakar dan gosong yang mengakibatkan kadar air kurang dari 3\%, hal ini dikarenakan pemberian suhu dalam yang terlalu tinggi. Selain itu juga sering terjadi teh hitam yang smokey atau berbau asap dikarenakan adanya kebocoran pada bagian alat pemanas.

Produk rusak berpengaruh pada keuntungan yang diperoleh perusahaan dikarenakan biaya dikeluarkan akan meningkat (Elmas, 2017). Produk teh hitam yang tidak sesuai dengan standar kadar air yaitu kurang dari 3\% akan mengakibatkan teh hitam menjadi kering, rapuh dan gosong. Produk teh hitam dengan kadar air kurang dari 3\% akan mengakibatkan adanya kerugian 
dikarenakan akan dijual dengan harga yang lebih rendah. Produk teh hitam yang tidak sesuai dengan standar kadar air yaitu lebih dari $4 \%$ akan ditangani dengan cara melakukan pengeringan kembali. Pengeringan kembali terhadap produk teh hitam dengan kadar air 4\% mengakibatkan adanya tambahan biaya produksi yang harus dikeluarkan oleh PT. Perkebunan Tambi Unit Perkebunan Bedakah. Tujuan penelitian ini adalah untuk menganalisis pelaksanaan pengendalian kualitas produk pada proses pengeringan teh hitam di PT. Perkebunan Tambi Unit Perkebunan Bedakah dan untuk mengetahui faktor-faktor yang menyebabkan kurang maksimalnya proses pengeringan teh hitam di PT. Perkebunan Tambi Unit Perkebunan Bedakah.

\section{METODE PENELITIAN}

Metode dasar penelitian yang dilakukan dalam penelitian ini adalah metode deskriptif. Tujuan dari penelitian deskriptif ini adalah untuk membuat deskripsi, gambaran, atau lukisan secara sistematis, faktual dan akurat mengenai fakta-fakta, sifat-sifat serta hubungan antar fenomena yang diselidiki (Nazir, 2014). Metode pelaksanaan penelitian dalam penelitian ini adalah studi kasus. Menurut Nazir (2014), studi kasus adalah penelitian mengenai status subyek penelitian yang berkenan dengan suatu fase spesifik atau khas dari keseluruhan personalitas.

Metode pengambilan sampel menggunakan sampel produk teh hitam yang baru keluar dari mesin pengeringan dan akan diuji kadar airnya sebanyak 2,5 gram setiap pengujian dan dilakukan pengujian sebanyak 5 kali untuk satu jenis bubuk teh hitam. Metode penentuan responden menggunakan metode purposive. Metode purposive menurut Sugiyono (2017) adalah teknik untuk menentukan responden penelitian dengan pertimbangan tertentu yang bertujuan agar data yang diperoleh lebih representatif. Adapun yang menjadi responden adalah kepala pabrik, kepala bagian pengolahan basah, kepala bagian pengolahan kering dan pembimbing pengeringan. Pertimbangan didasarkan pada responden yang memahami seluk beluk pengolahan teh hitam dari bahan baku sampai akhir khususnya proses pengeringan. 
Batubara, et.al., Analisis Pengendalian Kualitas Produk Teh Hitam Di PT ...

Data yang dikumpulkan adalah data primer dan data sekunder. Data primer diperoleh melalui wawancara, observasi, pencatatan dan dokumentasi untuk memperoleh data yang dibutuhkan mengenai pengendalian kualitas produk teh hitam berdasarkan proses pengeringan. Pengumpulan data sekunder diperoleh dari instansi terkait dan literatur yang berhubungan dengan penelitian berupa dokumen, data standar kualitas, laporan hasil produksi, kadar air dan lain-lain. Pengambilan data dilakukan bulan Maret 2020.

Pengujian data dilakukan dengan menggunakan analisis pengendalian kualitas statistik. Pengendalian kualitas statistik berarti melakukan pengendalian dengan metode statistik mulai dari bahan baku, selama proses produksi berlangsung sampai produk akhir dan selanjutnya disesuaikan dengan standar yang telah ditetapkan sehingga dapat menghasilkan produk yang berkualitas dan tidak cacat (Yuliasih, 2014). Statistik proses kontrol ini dibuat dengan tujuan untuk mendeteksi penyebab khusus yang mengakibatkan terjadinya kecacatan atau proses diluar kontrol sedini mungkin sehingga kualitas produk dapat dipertahankan (Wardhana et al, 2018). Analisis dilakukan dengan alat analisis berupa peta kendali X-bar Chart dan R Chart, kapabilitas proses yang terdiri dari Rasio Kapabilitas Proses (Cp) dan Indeks Kapabilitas Proses (Cpk), serta diagram sebab akibat.

\section{X-bar Chart dan R Chart}

Perhitungan peta kendali $\mathrm{X}$ bar dan $\mathrm{R}$ digunakan untuk melihat berapa banyak jumlah data yang berada diluar batas kontrol (out of control) (Meri et al, 2017). X-bar Chart digunakan untuk mengetahui rata-rata pengukuran antar sub group yang diperiksa. R Chart digunakan untuk mengetahui besarnya rentang atau selisih antara nilai pengukuran yang terbesar dengan nilai pengukuran terkecil di dalam sub group yang periksa. Adapun langkah-langkah yang digunakan sebagai berikut :

1. Menghitung nilai rata-rata $X$ dan

Range

a. Menentukan nilai $\mathrm{X}$ bar b. Menentukan nilai Range

$\mathrm{R}=\mathrm{X}_{\mathrm{i} \text { maks }}-\mathrm{X}_{\mathrm{i} \text { min }}$ 
$\bar{X}=\frac{\sum X}{\mathrm{k}}$

Keterangan :

$\bar{X}=$ Nilai rata-rata kadar air

$\mathrm{X}=$ Nilai kadar air

$\mathrm{k}=$ Jumlah subgrup

c. Menentukan nilai X-double bar

$\overline{\bar{X}}=\frac{\sum \bar{X}_{i}}{\mathrm{i}}$

Keterangan :

$\overline{\bar{X}}=$ Nilai $X$-double bar

$\bar{X}=$ Nilai rata-rata kadar air

$\mathrm{i}=$ Jumlah hari

2. Menentukan nilai tengah (CL) untuk

$\mathrm{X}$-bar Chart dan R Chart

a. CL untuk X-bar Chart

$\mathrm{CL}=\overline{\bar{X}}=\frac{\sum \bar{X}_{i}}{\mathrm{i}}$

Keterangan :

$\mathrm{CL}=$ Garis Pusat (Central Line)

$\overline{\bar{X}}=$ Nilai X-double bar

$\bar{X}=$ Nilai rata-rata kadar air

$\mathrm{i}=$ Jumlah hari

3. Menentukan batas atas kendali

(UCL) dan batas bawah kendali

(LCL) untuk peta kendali X-bar

Chart

a. Batas Atas Kendali (UCL)

$\mathrm{UCL}=\overline{\bar{X}}+(\mathrm{A} 2 \cdot \bar{R})$

Keterangan :

$\mathrm{UCL}=$ Batas Atas Kendali

$\overline{\bar{X}} \quad=$ Nilai $\mathrm{X}$-double bar

$\bar{R} \quad=$ Nilai $\mathrm{R}$ bar

A2 = Nilai dari tabel konstanta

kontrol chart

4. Menentukan batas atas kendali

(UCL) dan batas bawah kendali

(LCL) untuk peta kendali R Chart

a. Batas Atas Kendali (UCL)

$\mathrm{UCL}=\mathrm{D} 4 \cdot \bar{R}$

Keterangan :

$\mathrm{UCL}=$ Batas Atas Kendali

$\bar{R} \quad=$ Nilai $\mathrm{R}$ bar
Keterangan :

$\mathrm{R}=$ Nilai Range

$\mathrm{X}=$ Nilai kadar air

d. Menentukan nilai $\mathrm{R}$ bar

$\bar{R}=\frac{\sum R_{i}}{\mathrm{i}}$

Keterangan :

$\bar{R}=$ Nilai $\mathrm{R}$ bar

$R=$ Nilai Range

$\mathrm{i}=$ Jumlah hari

b. CL untuk R Chart

$\mathrm{CL}=\bar{R}$

Keterangan :

$\mathrm{CL}=$ Garis Pusat (Central Line)

$\bar{R}=$ Nilai $\mathrm{R}$ bar b. Batas Bawah Kendali (LCL)

$\mathrm{LCL}=\overline{\bar{X}}-(\mathrm{A} 2 . \bar{R})$

Keterangan :

$\mathrm{LCL}=$ Batas Bawah Kendali

$\overline{\bar{X}} \quad=$ Nilai $\mathrm{X}$-double bar

$\bar{R} \quad=$ Nilai $\mathrm{R}$ bar

A2 = Nilai dari tabel konstanta kontrol chart

b. Batas Bawah Kendali (LCL)

$\mathrm{LCL}=\mathrm{D} 3 \cdot \bar{R}$

Keterangan :

LCL $=$ Batas Bawah Kendali

$\bar{R} \quad=$ Nilai $\mathrm{R}$ bar 
Batubara, et.al., Analisis Pengendalian Kualitas Produk Teh Hitam Di PT ...

D4 = Nilai dari tabel konstanta

D3 = Nilai dari tabel konstanta kontrol chart kontrol chart

\section{Rasio Kapabilitas Proses (Cp)}

Rasio kapabilitas proses (Cp) adalah sebuah proses untuk memenuhi spesifikasi sedain dihitung dengan mengatur spesifikasi atas dan spesifikasi bawah dibagi 6 kali nilai standar deviasi dari populasi. Persamaan $\mathrm{Cp}$ dapat dilihat pada persamaan sebagai berikut.

$\mathrm{Cp}=\frac{\mathrm{USL}-\mathrm{LSL}}{6 \mathrm{~S}}$

Keterangan :

$\mathrm{Cp} \quad=$ Rasio Kapabilitas Proses

USL = Upper Specification Limit

LSL $\quad=$ Lower Spesification Limit

$\mathrm{S} \quad=$ Standar deviasi proses

Menurut Pratama \& Susanti (2018), sebuah proses dianggap capable apabila memiliki nilai $\mathrm{Cp}$ minimal 1. Jika nilai $\mathrm{Cp}$ lebih besar dari 1 , maka artinya pengendalian kualitas proses pengeringan teh hitam pada PT. Perkebunan Tambi Unit Perkebunan Bedakah masih berada dalam batas spesifikasi.

\section{Indeks Kapabilitas Proses (Cpk)}

Indeks kapabilitas proses (Cpk) adalah mengukur perbedaan antara hasil yang diarapkan dengan faktual atas produk teh yang dihasilkan. Dihitung dengan mencari nilai minimum antara batas spesifikasi atas dikurangi nilai rata-rata total kadar air dibagi 3 kali nilai standar deviasi dari populasi proses, dan nilai rata-rata kadar air dikurangi batas spesifikasi bawah dibagi 3 kali nilai standar deviasi dari populasi proses. Persamaan Cpk dapat dilihat pada persamaan sebagai berikut.

$\mathrm{Cpk}=\min \{(\mathrm{CPL}, \mathrm{CPU})\}$

$\mathrm{Cpk}=\min \left\{\left(\frac{\mathrm{USL}-\overline{\bar{X}}}{3 \mathrm{~S}}\right),\left(\frac{\overline{\bar{X}}-\mathrm{LSL}}{3 \mathrm{~S}}\right)\right.$

Keterangan :

Cpk = Indeks Kapabilitas Proses

USL = Upper Specification Limit 
Jurnal Dinamika Sosial Ekonomi, 22 (1) : 1-16

$\begin{array}{ll}\text { LSL } & =\text { Lower Spesification Limit } \\ \overline{\bar{X}} & =\text { Nilai X-double bar } \\ \mathrm{S} & =\text { Standar deviasi proses }\end{array}$

Jika nilai Cpk lebih besar dari 1, maka artinya pengendalian kualitas proses pengeringan teh hitam pada PT. Perkebunan Tambi Unit Perkebunan Bedakah masih berada dalam batas spesifikasi.

\section{HASIL DAN PEMBAHASAN}

\section{Pelaksanaan Pengendalian Kualitas Produk}

Analisis dilakukan dengan cara analisis pengendalian kualitas statistik atau Statistical Process Control (SPC). Menurut Heizer \& Render (2017) yang dimaksud dengan Statistical Process Control (SPC) adalah proses yang digunakan untuk memantau berbagai standar dengan melakukan pengukuran dan tindakan korektif selagi produk atau jasa sedang berada dalam proses produksi. Aktivitas pengendalian kualitas secara statistik dapat membantu dalam menekan jumlah produk yang rusak dan membantu proses produksi menjadi lebih baik (Darsono, 2013).

Analisis pengendalian kualitas pada proses pengeringan dilakukan dengan cara observasi terhadap kadar air dari masing-masing jenis bubuk teh hitam dan kemudian dikumpulkan di dalam lembar pemeriksaan atau check sheet. Data kadar air yang dikumpulkan pada lembar pemeriksaan atau check sheet digunakan untuk membuat peta kendali X-bar dan Range dan selanjutnya uji kapabilitas proses agar dapat mengetahui apakah pengendalian kualitas produk pada proses pengeringan teh hitam yang dilakukan di PT. Perkebunan Tambi Unit Perkebunan Bedakah masih dalam batas spesifikasi atau tidak. Dalam membuat peta kendali $\mathrm{X}$-bar dan Range perlu untuk menghitung nilai rata-rata $\mathrm{X}$ dan $\mathrm{R}$, garis pusat (CL), batas kendali atas (UCL) dan juga batas kendali bawah (LCL). Setelah melakukan perhitungan nilai rata-rata $\mathrm{X}$ dan $\mathrm{R}$, garis pusat (CL), batas kendali atas (UCL) dan batas kendali bawah (LCL) maka selanjutnya membuat grafik peta kendali X-bar dan Range dengan menggunakan Microsoft Excel.

Bubuk I 
Batubara, et.al., Analisis Pengendalian Kualitas Produk Teh Hitam Di PT ...

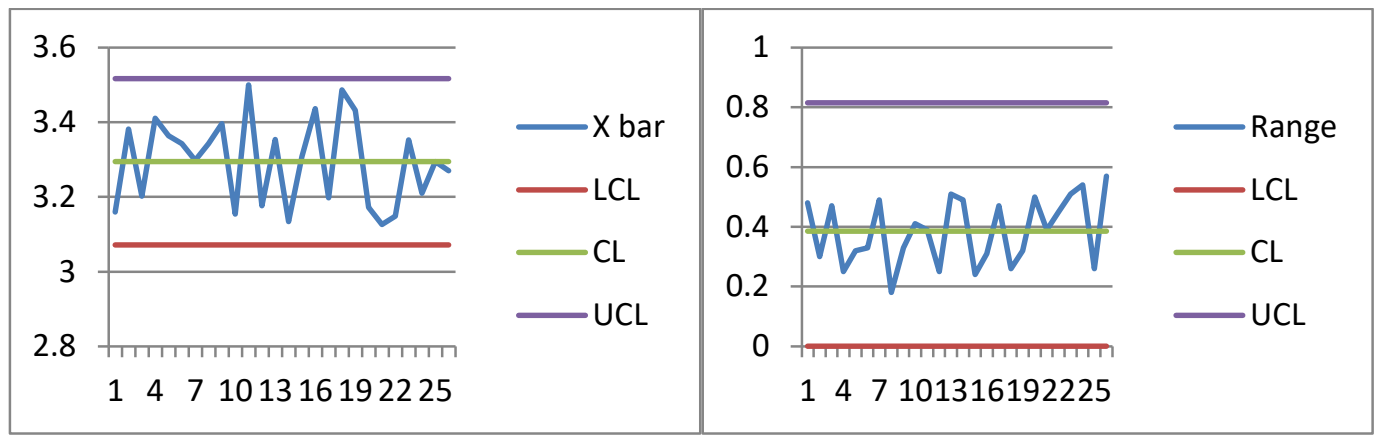

Gambar 1. Grafik peta kendali X-bar dan peta kendali R bubuk I

Sumber : Sumber: Data primer diolah (2020)

Dari hasil analisis peta kendali X-bar bubuk I dengan menggunakan Microsoft Excel diketahui nilai batas kendali atas (UCL) sebesar 3,51644, nilai batas kendali bawah (LCL) sebesar 3,07171 dan nilai tengah (CL) sebesar 3,29408. Dari gambar diketahui bahwa tidak ada satupun titik yang berada diluar dari batas kendali atas maupun batas kendali bawah, hal ini menunjukkan proses terkendali secara statistik. Dari hasil analisis peta kendali $\mathrm{R}$ bubuk I dengan menggunakan Microsoft Excel diketahui nilai batas kendali atas (UCL) sebesar 0,81469, nilai batas kendali bawah (LCL) sebesar 0 dan nilai tengah (CL) sebesar 0,38538. Dari gambar diketahui bahwa tidak ada satupun titik yang berada diluar dari batas kendali atas maupun batas kendali bawah, hal ini menunjukkan proses terkendali secara statistik.

Bubuk II

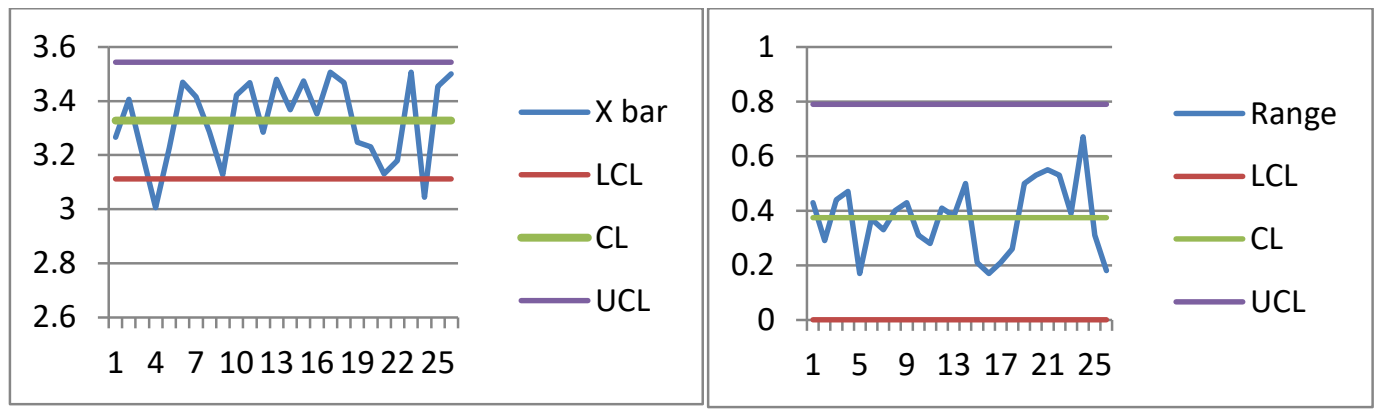

Gambar 2. Grafik peta kendali X-bar dan peta kendali R bubuk II

Sumber : Sumber: Data primer diolah (2020)

Dari hasil analisis peta kendali X-bar bubuk II dengan menggunakan Microsoft Excel diketahui nilai batas kendali atas (UCL) sebesar 3,54356, nilai batas kendali bawah (LCL) sebesar 3,11214 dan nilai tengah (CL) sebesar 
Jurnal Dinamika Sosial Ekonomi, 22 (1) : 1-16

3,32785. Dari gambar diketahui bahwa ada dua titik yang berada di luar dari batas kendali bawah, yaitu data ke 4 dengan nilai X bar sebesar 3,006 dan data ke 24 sebesar 3,044, hal ini menunjukkan proses berada di luar batas pengendalian statistik namun masih berada dalam batas spesifikasi yang ditetapkan oleh perusahaan. Dari hasil analisis peta kendali $\mathrm{R}$ bubuk II dengan menggunakan Microsoft Excel diketahui nilai batas kendali atas (UCL) sebesar 0,79031, nilai batas kendali bawah (LCL) sebesar 0 dan nilai tengah (CL) sebesar 0,37385. Dari gambar diketahui bahwa tidak ada satupun titik yang berada diluar dari batas kendali atas maupun batas kendali bawah, hal ini menunjukkan proses terkendali secara statistik.

Bubuk III

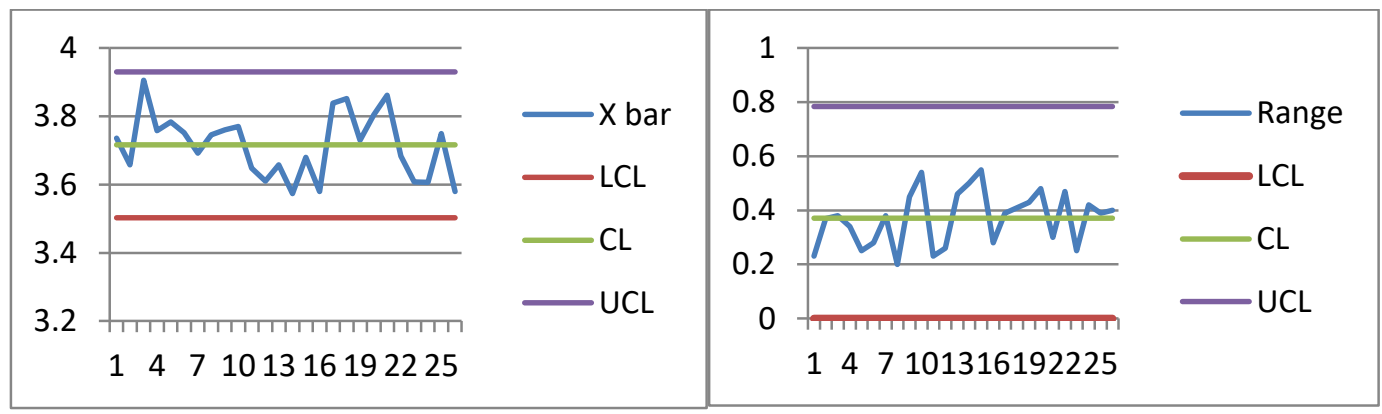

Gambar 3. Grafik peta kendali X-bar dan peta kendali R bubuk III

Sumber : Sumber: Data primer diolah (2020)

Dari hasil analisis peta kendali X-bar bubuk III dengan menggunakan Microsoft Excel diketahui nilai batas kendali atas (UCL) sebesar 3,93031, nilai batas kendali bawah (LCL) sebesar 3,50244 dan nilai tengah (CL) sebesar 3,71638. Dari gambar diketahui bahwa tidak ada satupun titik yang berada diluar dari batas kendali atas maupun batas kendali bawah, hal ini menunjukkan proses terkendali secara statistik. Dari hasil analisis peta kendali R bubuk III dengan menggunakan Microsoft Excel diketahui nilai batas kendali atas (UCL) sebesar 0,78380, nilai batas kendali bawah (LCL) sebesar 0 dan nilai tengah (CL) sebesar 0,37077. Dari gambar diketahui bahwa tidak ada satupun titik yang berada diluar dari batas kendali atas maupun batas kendali bawah, hal ini menunjukkan proses terkendali secara statistik.

Bubuk IV 
Batubara, et.al., Analisis Pengendalian Kualitas Produk Teh Hitam Di PT ...

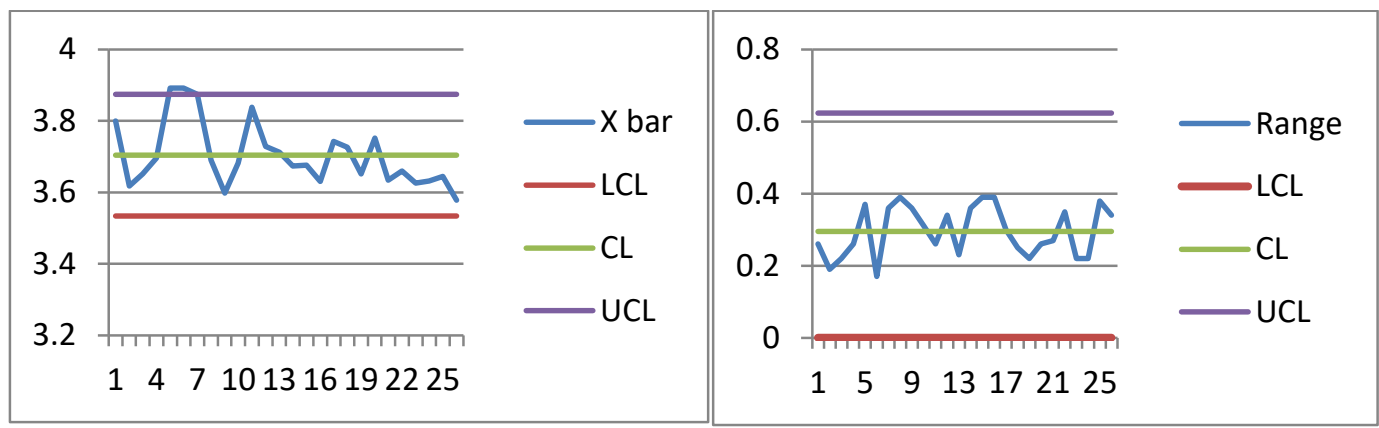

Gambar 4. Grafik peta kendali X-bar dan peta kendali R bubuk IV Sumber : Sumber: Data primer diolah (2020)

Dari hasil analisis peta kendali X-bar bubuk IV dengan menggunakan Microsoft Excel diketahui nilai batas kendali atas (UCL) sebesar 3,87398, nilai batas kendali bawah (LCL) sebesar 3,53355 dan nilai tengah (CL) sebesar 3,70377. Dari gambar diketahui bahwa ada tiga titik yang berada di luar dari batas kendali bawah, yaitu data ke 5 dengan nilai X bar sebesar 3,892, data ke 6 sebesar 3,892 dan data ke 7 sebesar 3,874, hal ini menunjukkan proses berada di luar batas pengendalian statistik namun masih berada dalam batas spesifikasi yang ditetapkan oleh perusahaan. Dari hasil analisis peta kendali R bubuk IV dengan menggunakan Microsoft Excel diketahui nilai batas kendali atas (UCL) sebesar 0,62363, nilai batas kendali bawah (LCL) sebesar 0 dan nilai tengah (CL) sebesar 0,295. Dari gambar diketahui bahwa tidak ada satupun titik yang berada diluar dari batas kendali atas maupun batas kendali bawah, hal ini menunjukkan proses terkendali secara statistik.

Bubuk Badag

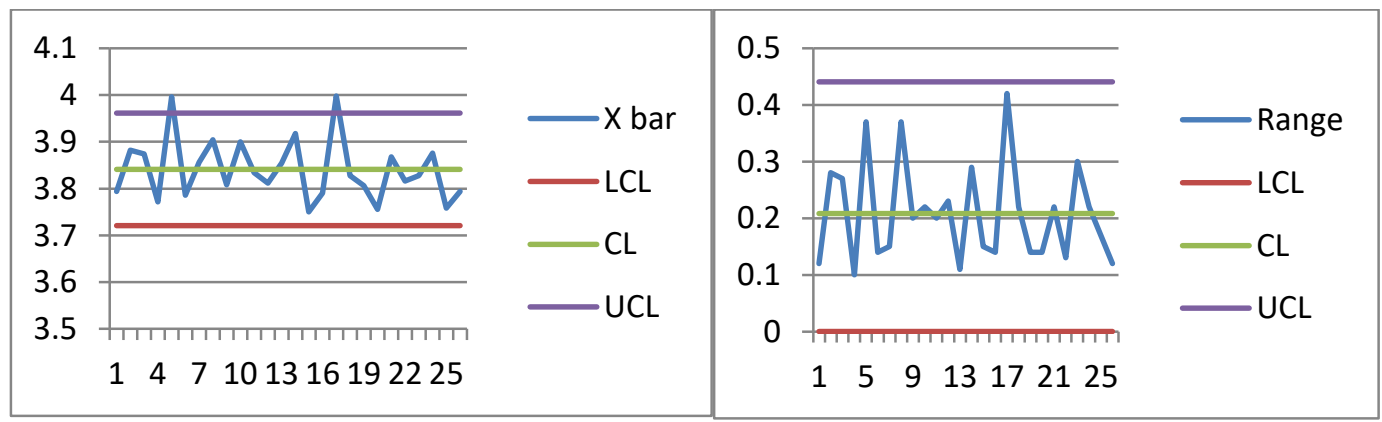

Gambar 5. Grafik peta kendali X-bar dan peta kendali R bubuk Badag Sumber : Sumber: Data primer diolah (2020) 
Jurnal Dinamika Sosial Ekonomi, 22 (1) : 1-16

Dari hasil analisis peta kendali X-bar bubuk badag dengan menggunakan Microsoft Excel diketahui nilai batas kendali atas (UCL) sebesar 3,96097, nilai batas kendali bawah (LCL) sebesar 3,72041 dan nilai tengah (CL) sebesar 3,84069. Dari gambar diketahui bahwa ada dua titik yang berada di luar dari batas kendali bawah, yaitu data ke 5 dengan nilai X bar sebesar 3,996 dan data ke 17 sebesar 3,998, hal ini menunjukkan proses berada di luar batas pengendalian statistik namun masih berada dalam batas spesifikasi yang ditetapkan oleh perusahaan. Dari hasil analisis peta kendali R bubuk badag dengan menggunakan Microsoft Excel diketahui nilai batas kendali atas (UCL) sebesar 0,44068, nilai batas kendali bawah (LCL) sebesar 0 dan nilai tengah (CL) sebesar 0,20846. Dari gambar diketahui bahwa tidak ada satupun titik yang berada diluar dari batas kendali atas maupun batas kendali bawah, hal ini menunjukkan proses terkendali secara statistik.

Dari hasil analisis peta kendali X-bar dan peta kendali $\mathrm{R}$ kelima jenis bubuk teh hitam, selanjutnya dilakukan uji kapabilitas proses dengan menghitung nilai Cp dan Cpk dari masing-masing jenis bubuk sebagai berikut :

Tabel 1. Perhitungan Kapabilitas Proses Pengeringan Teh Hitam

\begin{tabular}{cccccc}
\hline Jenis Bubuk & $\begin{array}{c}\text { Standar } \\
\text { Deviasi }\end{array}$ & USL & LSL & Cp & Cpk \\
\hline Bubuk I & 0,16568 & 4,28816 & 2,3 & 2 & 2 \\
Bubuk II & 0,16072 & 4,29217 & 2,36353 & 2 & 2 \\
Bubuk III & 0,15940 & 4,67278 & 2,75998 & 2 & 2 \\
Bubuk IV & 0,12682 & 4,46469 & 2,94285 & 2 & 2 \\
Badag & 0,08962 & 4,37841 & 3,30297 & 2 & 2 \\
\hline
\end{tabular}

Sumber: Data primer diolah (2020)

Berdasarkan hasil perhitungan kapabilitas proses bubuk I pada tabel 1 diketahui nilai standar deviasi sebesar 0,16568, USL sebesar 4,28816 dan LSL sebesar 2,3, dari perhitungan tersebut kemudian diperoleh nilai $\mathrm{Cp}$ dan $\mathrm{Cpk}$ sebesar 2. Berdasarkan hasil perhitungan kapabilitas proses bubuk II pada tabel 1 diketahui nilai standar deviasi sebesar 0,16072, USL sebesar 4,29217 dan LSL sebesar 2,36353, dari perhitungan tersebut kemudian diperoleh nilai Cp dan Cpk sebesar 2. Berdasarkan hasil perhitungan kapabilitas proses bubuk III pada tabel 1 diketahui nilai standar deviasi sebesar 0,15940, USL sebesar 4,67278 dan LSL 
Batubara, et.al., Analisis Pengendalian Kualitas Produk Teh Hitam Di PT ...

sebesar 2,75998, dari perhitungan tersebut kemudian diperoleh nilai Cp dan Cpk sebesar 2. Berdasarkan hasil perhitungan kapabilitas proses bubuk IV pada tabel 1 diketahui nilai standar deviasi sebesar 0,12682, USL sebesar 4,46469 dan LSL sebesar 2,94285, dari perhitungan tersebut kemudian diperoleh nilai $\mathrm{Cp}$ dan $\mathrm{Cpk}$ sebesar 2. Berdasarkan hasil perhitungan kapabilitas proses bubuk badag pada tabel 1 diketahui nilai standar deviasi sebesar 0,08962, USL sebesar 4,37841 dan LSL sebesar 3,30297, dari perhitungan tersebut kemudian diperoleh nilai Cp dan Cpk sebesar 2.

Berdasarkan hasil perhitungan kapabilitas proses keseluruhan jenis bubuk diketahui bahwa nilai $\mathrm{Cp}$ dan $\mathrm{Cpk}$ adalah 2 yang dimana nilai tersebut adalah baik dikarenakan lebih besar daripada 1 . Nilai $\mathrm{Cp}$ dan $\mathrm{Cpk}$ lebih besar daripada 1 artinya adalah pengendalian kualitas produk pada proses pengeringan teh hitam di PT. Perkebunan Tambi Unit Perkebunan Bedakah berada dalam batas spesifikasi yang sudah ditetapkan oleh perusahaan yaitu sebesar 3-4\% kadar air.

\section{Faktor-Faktor Yang Menyebabkan Kurang Maksimalnya Proses Pengeringan}

Untuk mencari penyebab adanya penyimpangan yang menyebabkan kurang maksimalnya proses pengeringan teh hitam, maka perlu untuk mengidentifikasi secara menyeluruh dengan menggunakan diagram fishbone atau diagram sebab akibat. Menurut Nasution (2005), Diagram Sebab Akibat adalah suatu pendekatan terstruktur yang memungkinkan dilakukan suatu analisis lebih terperinci dalam menemukan penyebab-penyebab suatu masalah, ketidaksesuaian, dan kesenjangan yang terjadi.Fishbone diagram (diagram tulang ikan) memiliki fungsi dalam yaitu untuk mengidentifikasi penyebab-penyebab yang kemungkinan timbul dari suatu efek spesifik (Rucitra et al, 2019). Adapun faktor-faktor yang menyebabkan kurang maksimalnya proses pengeringan teh hitam adalah faktor bahan baku (material), mesin (machine), tenaga kerja (man), metode kerja (method) dan lingkungan (environment).

Faktor bahan baku berupa bahan baku yang merupakan petikan kasar sehingga terdapat banyak daun tua dan mengakibatkan hasil analisis pucuk kurang dari 50\% sehingga tidak memenuhi syarat olah. Faktor mesin berupa adanya 
Jurnal Dinamika Sosial Ekonomi, 22 (1) : 1-16

kendala kerusakan pada mesin seperti pada tungku pembakaran sehigga menghasilkan panas yang tidak maksimal. Mesin yang digunakan juga sudah tergolong tua sehingga spesifikasinya kalah dengan mesin baru dan ketersediaan mesin pengeringan yang hanya tersedia dua buah. Faktor tenaga kerja berupa tenaga kerja tidak bekerja sesuai dengan SOP yang berlaku di perusahaan dan belum adanya pelatihan rutin bagi karyawan agar bisa meningkatkan pengetahuan dan keterampilan karyawan dala memproduksi teh hitam. Faktor metode kerja berupa metode kerja pada bagian pengeringan seperti pemberian suhu dan kapasitas mesin pengeringan tidak sesuai dengan prosedur yang ditetapkan oleh perusahaan. Faktor lingkungan berupa layout pabrik yang terlalu tertutup dan pengaruh cuaca yang tidak menentu, jika musim penghujan akan menghasilkan pucuk teh yang tinggi kadar airnya sedangkan jika musim kemarau akan menghasilkan pucuk teh yang sedikit kadar airnya sehingga pada proses pengeringan dibutuhkan penanganan lebih.

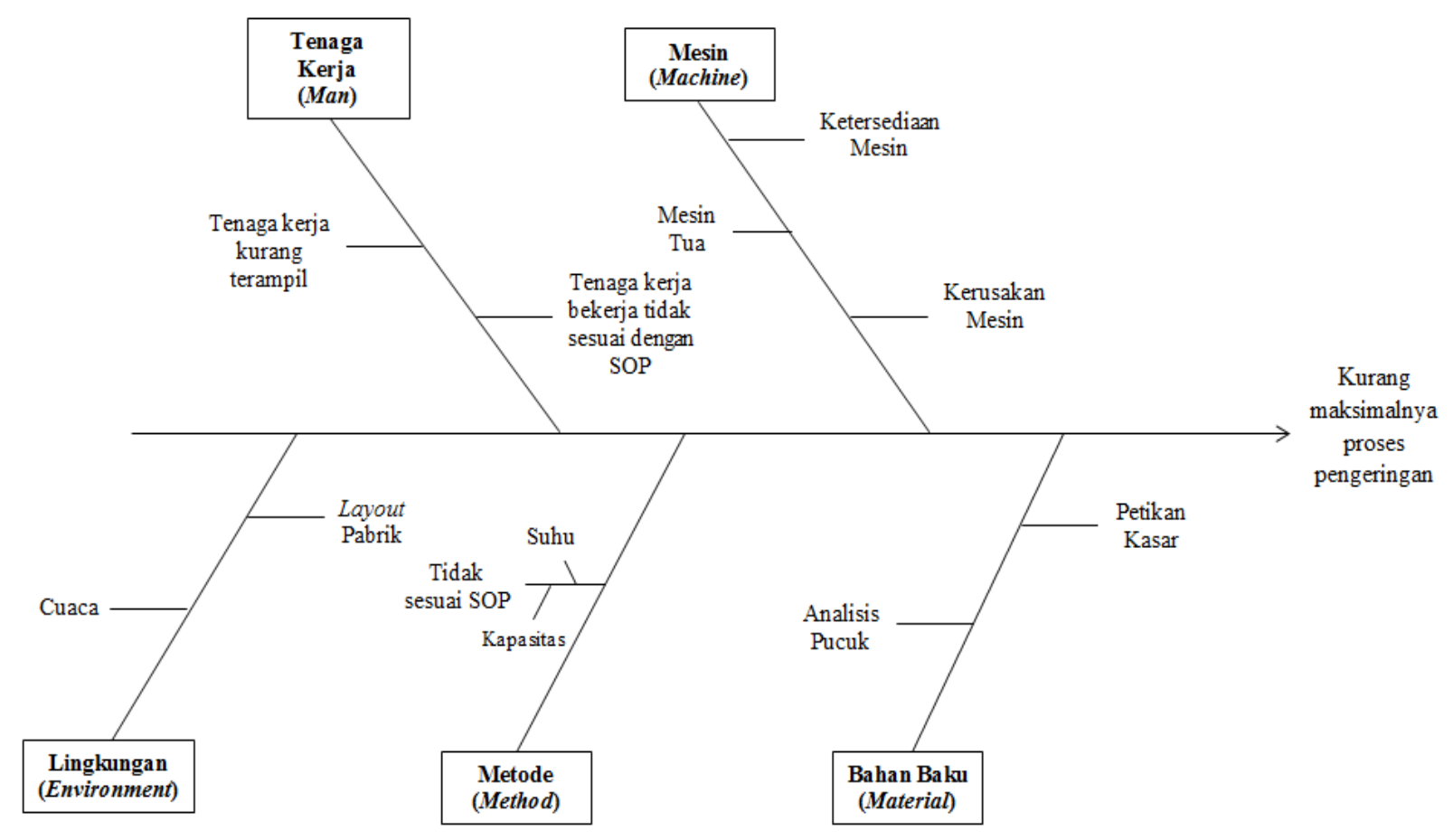

Gambar 6. Diagram Sebab Akibat (Fishbone)

Sumber: Data primer diolah (2020) 
Batubara, et.al., Analisis Pengendalian Kualitas Produk Teh Hitam Di PT ...

\section{SIMPULAN}

Pelaksanaan pengendalian kualitas produk pada proses pengeringan teh hitam di PT. Perkebunan Tambi Unit Perkebunan Bedakah masih berada dalam batas spesifikasi. Adapun faktor-faktor yang menyebabkan kurang maksimalnya proses pengeringan teh hitam di PT. Perkebunan Tambi Unit Perkebunan Bedakah adalah faktor bahan baku, mesin, tenaga keja, metode kerja dan lingkungan.

Pihak perusahaan atau pembimbing pemetikan perlu melakukan pengawasan maksimal terhadap pemetikan bahan baku secara rutin agar bahan baku yang dipetik tidak terlalu tua dan memenuhi standar analisa petik $50 \%$. Perusahaan perlu melakukan perawatan dan perbaikan mesin-mesin yang digunakan secara rutin agar dapat meminimalisir terjadinya hambatan pada saat proses produksi berlangsung. Perusahaan perlu memberikan pelatihan khusus terkait pengolahan teh hitam kepada karyawan yang bekerja di bagian produksi agar karyawan dapat meningkatkan pengetahuan dan keterampilan dari karyawan tersebut. Pihak perusahaan perlu melakukan pengawasan yang maksimal terhadap karyawan saat proses produksi berlangsung agar karyawan dapat bekerja sesuai dengan SOP (Standar Operasional Prosedur) yang berlaku.

\section{DAFTAR PUSTAKA}

Assauri, Sofjan. (2004). Manajemen Pemasaran. Jakarta: Rajawali Press.

Darsono. (2013). Analisis Pengendalian Kualitas Produksi dalam Upaya Mengendalikan Tingkat Kerusakan Produk. Jurnal Ekonomi Manajemen Akuntansi, 20 (35), 1-17

Elmas, Muhammad Syarif H. (2017). Pengendalian Kualitas dengan Menggunakan Metode Statistical Quality Control (SQC) Untuk Meminimumkan Produk Gagal Pada Toko Roti Barokah Bakery. Jurnal Penelitian Ilmu Ekonomi, 7(1), 15-22

Gaspersz, Vincent. (2001). Total Quality Management : Untuk Praktisi Bisnis dan Industri. Jakarta: PT. Gramedia Pustaka Utama.

Hariyanto, Agus. M. (2017). Pengendalian Kualitas Produk Roti Tawar "Della" Menggunakan Metode Statistical Process Control. Simki - Economic, 1(5), $1-15$. 
Jurnal Dinamika Sosial Ekonomi, 22 (1) : 1-16

Heizer, Jay and Render, Barry. (2017). Manajemen Operasi: Manajemen Keberlangsungan dan Rantai Pasokan Edisi 11. Jakarta: Salemba.

Meri, Mufrida, Irsan, Hendri Wijaya. (2017). Analisis Pengendalian Kualitas Pada Produk SMS (Sumber Minuman Sehat) Dengan Metode Statistical Process Control (SPC) Studi Kasus Pada Pt. Agrimitra Utama Persada Padang. Jurnal Teknologi, 7(1), 119-126.

Nasution, M. N.(2005). Manajemen Mutu Terpadu: Total Quality Management, Edisi Kedua. Bogor: Ghalia Indonesia.

Nazir. (2014). Metode Penelitian. Jakarta: Ghalia Indonesia.

Pratama, Yoga, Susanti, Lisa Harni. (2018). Kapabilitas Proses Mesin Pengemas Produk Pangan Bubuk:Studi Kasus pada Produk Tepung Terigu. Jurnal Aplikasi Teknologi Pangan, 7(1), 7-11.

Rucitra, A.L. dan S, Fadiah. (2019). Penerapan Statistical Quality Control (SQC) Pada Pengendalian Mutu Minyak Telon (Studi Kasus Di Pt.X). Jurnal Agrointek, 13(1), 72-81.

Sidartawan, R. (2014). Analisa Pengendalian Proses Produksi Snack Menggunakan Metode Statistical Process Control (SPC). Jurnal Rotor, 7(2), 10-14.

Sugiyono. (2017). Metode Penelitian Kuantitatif, Kualitatif dan R\&D. Bandung: Penerbit Alfabeta.

Wardhana, Marcelly Widya, Sulastri, Eko Adi Kurniawan. (2018). Analisis Peta Kendali Variabel Pada Pengolahan Minyak Sawit Dengan Pendekatan Statistical Quality control (SQC). Jurnal Rekayasa, Teknologi dan Sains, 2(1), 27-34

Yuliasih, Ni Kadek. (2014). Analisis Pengendalian Kualitas Produk pada Perusahaan Garmen Wana Sari Tahun 2013. E-journal Undiksha, 4(1), 112. 